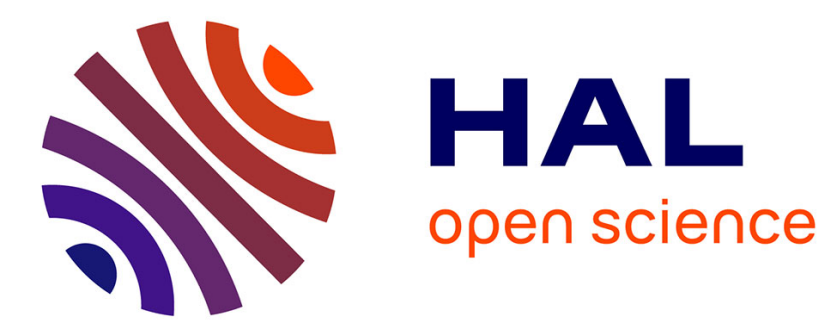

\title{
Evidence of hydrogen modulation in amorphous germanium prepared by reactive evaporation
}

S. Houssaïni, M. Vergnat, A. Bruson, G. Marchal, Ph. Mangin, C. Vettier

\section{To cite this version:}

S. Houssaïni, M. Vergnat, A. Bruson, G. Marchal, Ph. Mangin, et al.. Evidence of hydrogen modulation in amorphous germanium prepared by reactive evaporation. Applied Physics Letters, 1993, 63 (15), pp.2109-2111. 10.1063/1.110555 . hal-02113406

\section{HAL Id: hal-02113406 https://hal.science/hal-02113406}

Submitted on 28 Apr 2019

HAL is a multi-disciplinary open access archive for the deposit and dissemination of scientific research documents, whether they are published or not. The documents may come from teaching and research institutions in France or abroad, or from public or private research centers.
L'archive ouverte pluridisciplinaire HAL, est destinée au dépôt et à la diffusion de documents scientifiques de niveau recherche, publiés ou non, émanant des établissements d'enseignement et de recherche français ou étrangers, des laboratoires publics ou privés. 


\title{
Evidence of hydrogen modulation in amorphous germanium prepared by reactive evaporation
}

\author{
S. Houssaïni, M. Vergnat, A. Bruson, G. Marchal, and Ph. Mangin \\ Laboratoire de Métallurgie Physique et Sciences des Matériaux (U. R. A. au C. N. R. S. No. 155), \\ Université de Nancy I, B. P. 23954506 Vandoeuvre-les-Nancy Cedex, France \\ C. Vettier \\ Institut Laüe Langevin, B. P, 156X, 38042 Grenoble Cedex, France, and European Synchrotron Research \\ Facility, B. P. 220, 38043 Grenoble Cedex, France.
}

(Received 2 December 1992; accepted for publication 11 August 1993)

\begin{abstract}
Reactive evaporation of germanium under a flow of hydrogen atoms on substrates maintained at liquid-nitrogen temperature allows us to obtain $a$-Ge:H thin films and multilayers. The material contains a considerable amount of polygermane bonds and is porous, as shown by low angle $x$-ray scattering performed on $\mathrm{Ge} / \mathrm{Ge}: \mathrm{H} / \ldots$ multilayers. The stability of hydrogen is measured by resistivity measurements and by effusion experiments. Finally, low angle neutron scattering shows that it is possible to modulate hydrogen in $\mathrm{Ge} / \mathrm{Ge}: \mathrm{H} / \mathrm{Ge} / \mathrm{Ge}: \mathrm{D} / \ldots$ multilayers with $40 \AA$ thick layers.
\end{abstract}

Recently, we have shown that the technique of reactive evaporation allows one to obtain amorphous multilayers of hydrogenated silicon ${ }^{1}$ and of hydrogenated silicon tin alloys. ${ }^{2}$ In this letter, we show that multilayers of germanium can also be obtained by this preparation method. As the aim of this study is to observe the modulation of hydrogen in very thin layers, it is necessary to suppress diffusion over very short distances. Shinar et al. ${ }^{3}$ have reported the absence of long-range $\mathrm{H}$ motion in amorphous silicon if the material was void-rich and contained a lot of $\mathrm{SiH}_{2}$ bonds. These films were obtained with low substrate temperatures. In order to obtain this microstructure, we prepared hydrogenated amorphous germanium by evaporation under a flow of hydrogen atoms on substrates maintained at liquid-nitrogen temperature. The hydrogen bonding is characterized by infrared spectrometry and the porosity is observed by performing low angle $x$-ray scattering on $\mathrm{Ge} / \mathrm{Ge}: \mathrm{H} / .$. multilayers, then, the stability of hydrogen is measured by resistivity measurements and effusion experiments. Finally, we show that low angle neutron scattering allows one to observe the modulation of hydrogen and deuterium in $\mathrm{Ge} / \mathrm{Ge}: \mathrm{H} / \mathrm{Ge} / \mathrm{Ge}: \mathrm{D} / \ldots$ multilayers.

Amorphous $\mathrm{Ge:H}$ is usually prepared by glow discharge $e^{4}$ or by sputtering and only one attempt ${ }^{5}$ has been made to hydrogenate evaporated germanium. In this study, germanium was evaporated from an electron beam gun crucible. The deposition rate, monitored and controlled by a quartz microbalance system, was the equivalent of 1.1 $\AA / s$ of pure Ge of bulk density. The substrates were kept at liquid-nitrogen temperature in order to increase the hydrogen concentration and to avoid hydrogen diffusion in the multilayers. Atomic hydrogen was produced by thermal dissociation of molecular hydrogen in a tungsten tube heated to $2400 \mathrm{~K}$. The hydrogen flow was regulated by maintaining the total pressure in the evaporation chamber of $6 \times 10^{-5}$ Torr.

The first characteristic of these samples is that they contain essentially $\mathrm{GeH}_{2}$ bonds. Indeed, the infrared transmission spectrum of a freshly prepared film (Fig. 1) shows four strong absorption bands due to the $\left(\mathrm{GeH}_{2}\right)_{n}$ polyger- mane bonding geometry: ${ }^{6}(1)$ unresolved symmetric and asymmetric stretching modes at $1980 \mathrm{~cm}^{-1}$; (2) the 825 $\mathrm{cm}^{-1}$ scissors mode; (3) the $765 \mathrm{~cm}^{-1}$ wagging mode; and (4) the $570 \mathrm{~cm}^{-1}$ rocking mode. The $1880 \mathrm{~cm}^{-1}$ absorption associated with isolated Ge:H bonds is hardly visible. Moreover, the spectra show an immediate and rapid atmospheric post-oxidation with time. Therefore, in order to avoid post-oxidation, the samples were placed, just after the deposition process, in a liquid-nitrogen container and they were maintained at this temperature until the other characterization experiments (exodiffusion, diffraction) can be carried out.

The second feature is the low density of hydrogenated germanium which was previously ${ }^{7}$ observed from $x$-ray scattering experiments performed on $\mathrm{Ge} / \mathrm{Ge}: \mathrm{H}$ multilayers prepared by evaporation of germanium alternately with and without hydrogen during $30 \mathrm{~s}$ stages. Such multilayers give rise to Bragg peaks in low angle $x$-ray scattering, the intensity of which is a function of the contrast between the layers. This multilayer is stable since the peaks are always visible after an annealing at $350^{\circ} \mathrm{C}$. As the $\mathrm{x}$-ray scattering factor from hydrogen is very weak, the modulation of hydrogen in the material leads to an insignificant signal and it is not the origin of the $x$-ray scattering peaks. In fact, the

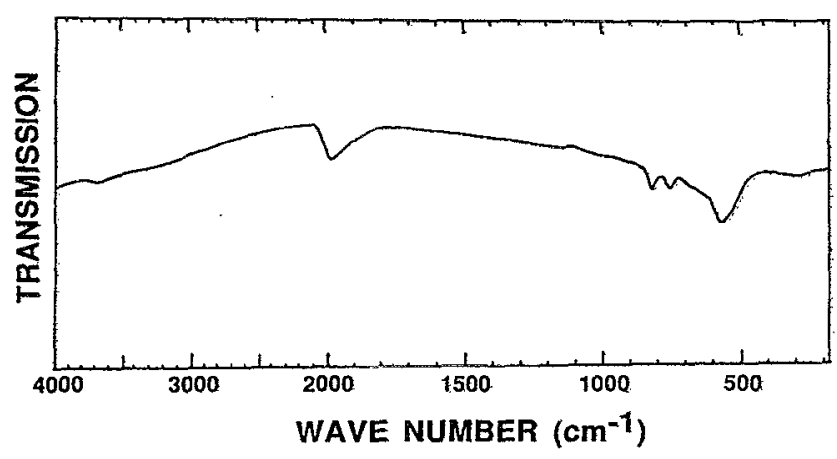

FIG. 1. Infrared transmission spectrum of evaporated $a-G e: H$ deposited at $77 \mathrm{~K}$. 


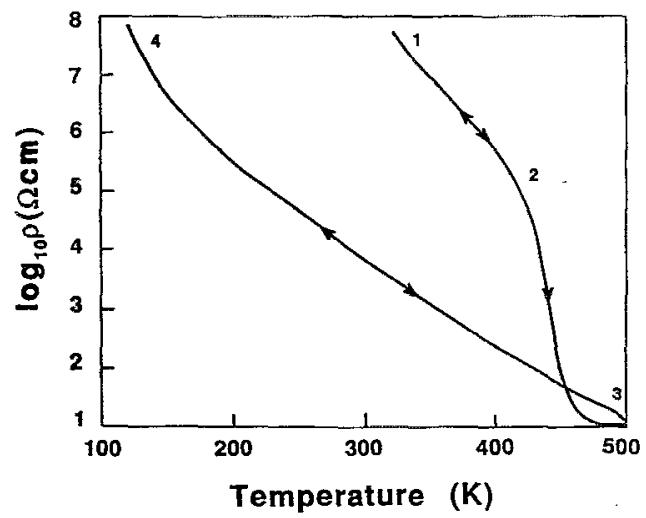

FIG. 2. Variation of the de resistivity of $a-\mathrm{Ge}: \mathrm{H}$ sample vs temperature.

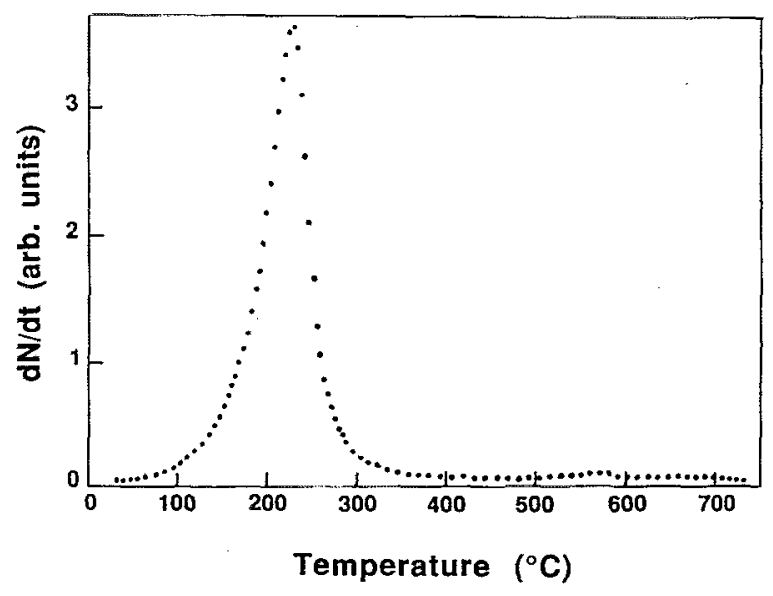

FIG. 3. Effusion spectrum of a deuterated germanium sample. The heating rate is $15^{\circ} \mathrm{C} / \mathrm{min}$.

characterization (hydrogen bonding, porosity) described in the first sections. Moreover, taking account of the different heating rates, the maximum temperature of the effusion curve corresponds to the transition temperature observed in the resistivity measurements.

Complementary information on the mobility of hydrogen can be obtained by low angle neutron scattering experiments performed on multilayers with a modulation of hydrogen and deuterium. Indeed, as the neutron coherent scattering amplitudes of $H$ and $D$ are large and of the opposite sign, neutron diffraction experiments are very sensitive to the isotope introduced in the evaporation chamber during the germanium deposition. Low angle neutron scattering experiments were performed on a $\mathrm{Ge} / \mathrm{Ge}: \mathrm{H} / \mathrm{Ge} /$ $\mathrm{Ge}: \mathrm{D} / \ldots$ sample at the D10 instrument of the Institute Lauie Langevin. The theoretical thickness of each layer was $33 \AA$. The spectrum (Fig. 4) shows the peak at $0.078 \AA^{-1}$ corresponding to that observed with $\mathrm{x}$-ray experiments and attributed to the silicon density modulation. In fact, as the average of $b_{\mathrm{H}}$ and $b_{\mathrm{D}}$ is not zero, this peak is due both to the atomic density modulation and to the hydrogen modulation. In addition, there is a large prepeak at $0.039 \AA^{-1}$, which is a superstructure peak, due to the fact that hydro-

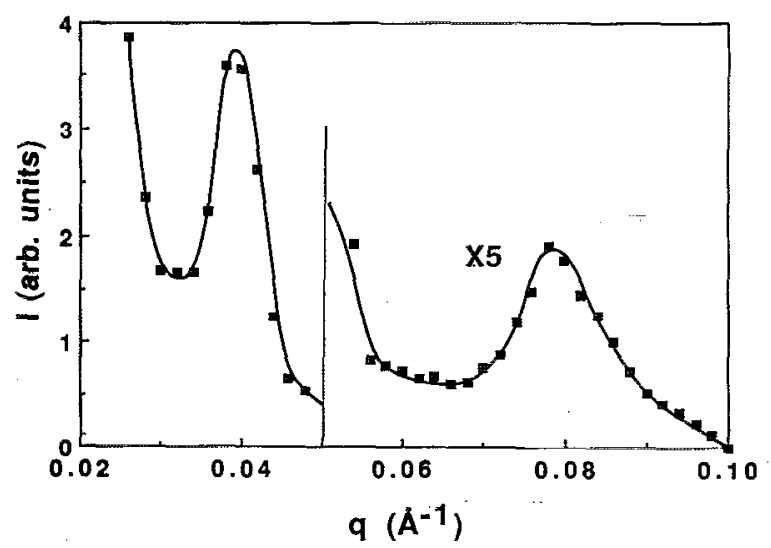

FIG. 4. Low angle neutron scattering intensity $I$ vs scattering vector $q$ for $\mathrm{Ge} / \mathrm{Ge}: \mathrm{H} / \mathrm{Ge} / \mathrm{Ge}: \mathrm{D} / . .$. multilayers. 
gen and deuterium are alternating with a double modulation period of $160 \AA$. The modulation wavelength is larger than the theoretical thickness ( $132 \AA$ ) because of the lower density of the hydrogenated and deuterated films. Moreover, this superstructure peak disappears rapidly at $300 \mathrm{~K}$ due to the diffusion of hydrogen and deuterium and it is necessary to keep the samples carefully at $77 \mathrm{~K}$ before the experiments in order to maintain the isotopic modulation. As expected, the diffusivity of hydrogen in germanium is then much larger than the diffusivity measured in amorphous silicon ${ }^{9}$ prepared by the same technique, in which neutron experiments can be carried out in the range 250 $300^{\circ} \mathrm{C}$.

In conclusion, $a-\mathrm{Ge}: \mathrm{H}$ thin films and multilayers can be obtained by evaporation on a substrate maintained at liquid-nitrogen temperature under a flow of atomic hydrogen. This material is porous, as shown by low angle $\mathrm{x}$-ray scattering, and contains essentially $\mathrm{GeH}_{2}$ or $\left(\mathrm{GeH}_{2}\right)_{n}$ bonds. Resistivity measurements and exodiffusion experiments show that hydrogen leaves the samples at about $200^{\circ} \mathrm{C}$, depending on the heating rate. Moreover, the low value of the hydrogen motion allows the observation at 300 $\mathrm{K}$ of an isotopic modulation with $40 \AA$ thick layers by performing low angle neutron scattering experiments.

The authors are indebted to A. Burneau for his help in infrared spectrometry measurements.

${ }^{1}$ M. Vergnat, S. Houssaïni, C. Dufour, A. Bruson, G. Marchal, Ph. Mangin, R. Erwin, J. J. Rhyne, and C. Vettier, Phys. Rev. B 40, 1418 (1989).

${ }^{2}$ S. Houssaïni, M. Vergnat, A. Bruson, G. Marchal, and C. Vettier, J. Appl. Phys. 73, 483 (1993).

${ }^{3}$ J. Shinar, R. Shinar, S. Mitra, and J. Y. Kim, Phys. Rev. Lett. 62, 2001 (1989).

${ }^{4}$ W. Paul, S. J. Jones, W. A. Turner, and P. Wickboldt, J. Non-Cryst. Solids 141, 271 (1992).

${ }^{5}$ S. H. Yang and W. J. Lee, Solid State Commun. 53, 993 (1985).

${ }^{6} \mathrm{G}$. Lucovsky, J. Non-Cryst. Solids 76, 173 (1985).

${ }^{7}$ M. Vergnat, S. Houssaini, A. Bruson, B. George, G. Marchal, Ph. Mangin, and J. P. Stoquert, Key Eng. Mater. 40 \& 41, 311 (1990).

${ }^{8}$ W. Beyer, Physica B 170, 105 (1991).

${ }^{9} \mathrm{M}$. Vergnat, S. Houssaïni, C. Dufour, A. Bruson, G. Marchal, Ph. Mangin, R. Erwin, J. J. Rhyne, and C. Vettier, Europhys. Lett. 14, 457 (1991). 